\title{
Residência multiprofissional no contexto do Sistema Único de Saúde: perspectivas e contradições
}

\section{Resumo}

Luciana da Conceição e Silva*

Este artigo contextualiza o atual momento de fragilização do Sistema Único de Saúde (SUS) que se traduz em contradições concernentes aos projetos em disputas na saúde. Nesse contexto, discutimos a implementação do programa de Residência Multiprofissional em Saúde (RMS). Tal programa, que propõe formação para fortalecer o SUS, convive com uma realidade de precarização da política de saúde, trabalho e desfinanciamento do sistema público de saúde. Compreende-se a RMS como estratégia do movimento sanitarista para fortalecer a formação de um perfil profissional articulado às necessidades sociais da população. Problematizaremos, portanto, os dilemas da formação através do trabalho proposto pela RMS e sua estratégia de expansão no país.

Palavras-chave: residência; educação, saúde; capitalismo.

\section{Multiprofissional residency in the context of the unified health system: perspectives and contradictions}

\begin{abstract}
This article analyzes the current state of embrittlement of the Unified Health System (SUS) which translates into contradictions concerning the projects in disputes on health. In this context we discussed the implementation of the Multidisciplinary Residency Program in Health (RMS). This program offers training to strengthen the SUS coexists with a precarious reality of health policy work and public health system underfinanced. It is understood the RMS as the sanitation movement strategy to strengthen the formation of a professional profile articulated social needs of the population, however, we question the dilemmas of education through work proposed by the RMS and its expansion strategy in the country.
\end{abstract}

Keywords: residency; education, health; capitalism.

Recebido em: 02/02/2017

Aprovado em:05/04/2017

\footnotetext{
* Especialista em Saúde da Mulher pelo Programa de Residência Multiprofissional da UFRJ. Mestranda em Serviço Social (PUC-Rio). Assistente Social na Secretaria de Saúde do Município de Carapebus/RJ e no Programa Estadual de Transplantes do Rio de Janeiro.
} 


\section{Introdução}

Neste artigo objetiva-se discutir a implementação do programa de Residência Multiprofissional em Saúde (RMS) ${ }^{1}$ no âmbito do Sistema Único de Saúde (SUS), entendida como uma importante estratégia do reforço para a perspectiva da Reforma Sanitária na saúde. Partimos do pressuposto de que o contexto de implementação das RMS no país, diante das contrarreformas no SUS, é cercado pelo conflito entre os projetos em disputas na saúde. Por isso, discutiremos as atuais ações contrárias ao sistema público de saúde, objetivando contextualizar os esforços do capital para fortalecer a proposta mercantil no SUS. A partir da Constituição Federal de 1988, no seu artigo 200, inciso III, passou a ser competência do SUS a ordenação da formação de recursos humanos na área da saúde.

Muitas discussões surgiram sobre o modelo do profissional de saúde, no sentido de romper o tradicional modelo biomédico, centrado no hospital e na atenção curativa, com profissionais segregados em especialidades. Até hoje se busca um modelo orientado para a integralidade da assistência, centrado na promoção da saúde, no qual os profissionais executem suas funções de forma multidisciplinar.

Ao se propor um novo modelo de atenção, propõe-se também um novo perfil profissional, sendo imprescindível para o sucesso da nova estratégia que tanto os novos quanto os antigos integrantes assumam o compromisso com a remodelação, adquirindo e mantendo esse novo perfil.

Nessa conjuntura, os Programas de Residência Multiprofissional em Saúde foram pensados com o objetivo de contribuir para a revisão do modelo assistencial, na medida em que podem formar um novo perfil do profissional de saúde preparado para responder às reais necessidades de saúde da população, tendo em vista a atual centralidade da expansão da atenção básica, a partir do modelo assistencial da Estratégia Saúde da Família (ESF) no país.

Consideramos que, no contexto avesso ao SUS universal e de qualidade, a alternativa para resistir aos ditames do capital é formar profissionais/intelectuais críticos e consonantes com os princípios e diretrizes do SUS para que a relativa autonomia reservada aos profissionais de nível superior possa ser aproveitada a favor da luta pela saúde coletiva.

\section{Mundialização do capital e consequências na atual configuração das políticas sociais}


No contexto histórico de desenvolvimento do capitalismo, identificamos, a partir de Chesnais (1996), particularmente, três períodos que se articulam, conformando fases específicas do modo de produção do capital. São eles: o período compreendido entre os anos de 1880 e 1913, o qual se convencionou designar de capitalismo monopolista; o período que se inicia após a segunda grande guerra e que teve seu crepúsculo entre os anos 1974-1979 período conhecido como os "trinta anos gloriosos", no qual imperaram o fordismo e a regulação keynesiana (Welfare State) - e, por fim, encontramos o período atual, emergido com o ocaso dos "anos de ouro", no final da década dos anos de 1970 e que aqui se denomina de fase de mundialização do capital.

Ao tratarmos da mundialização do capital, estamos nos referindo a uma "nova configuração do capitalismo mundial e nos mecanismos que comandam seu desempenho e sua regulação” (CHESNAIS, 1996, p.13). Para Chesnais (1996:15), o que qualifica a mundialização como nova e mais recente fase de desenvolvimento capitalista é que, apesar de persistirem aspectos das fases anteriores, o sentido e o conteúdo da acumulação de capital e dos seus resultados são bem diferentes. Nesse sentido, a posição de centralidade ocupada pelo capital financeiro, no que concerne à acumulação capitalista, atua como fator preponderante na distinção da mundialização como uma nova fase.

As grandes empresas, corporações e conglomerados transnacionais traçam políticas de produção, comercialização e conquista de mercado, planejam e controlam estratégias de acumulação, induzindo as decisões governamentais dos países, regiões e do mundo, a fim de que ajam conforme os seus interesses. Assim, a globalização do capital leva a um declínio da autonomia do Estado-nação, visto que a sua soberania é reduzida, pois diretrizes e decisões importantes passam a ser compartilhadas com os centros de poder mundiais.

Embora os Estados nacionais sejam combatidos pelas estruturas de poder globais, estas se apoiam neles para administrarem a dívida interna e externa e desregulamentar a economia, entre outros aspectos. Consequentemente, à medida que a acumulação capitalista se transforma, leva a uma mudança na forma do Estado. Esse redimensionamento do papel do Estado nos dias atuais está intimamente associado ao declínio do modo de produção fordista e ao crescimento da produção flexível, no contexto da mundialização econômica, legitimando a revitalização dos ideais liberais. A (contra) reforma do Estado, então, é legitimada pelo neoliberalismo, cujos princípios básicos são essencialmente: o individualismo exacerbado, o Estado mínimo e a desregulação do mercado (DRAIBE, 1993). 
A partir na década de 1990, apresentam-se na América Latina e no Brasil alguns programas voltados para o crescimento econômico com o desenvolvimento social, porém, também "não puderam fugir do movimento de internacionalização da economia, incorporando-se à dinâmica mais geral dos processos especulativos" (MOTA, 2010: 155). Na atualidade, o neodesenvolvimentismo se configura nessa proposta de desenvolvimento que supõe "romper" com a proposta neoliberal.

Assim, o neodesenvolvimentismo se expressa com mais força perante a crise neoliberal, iniciada nos anos 2000. A questão principal, colocada em tela pelo neodesenvolvimentismo, é que para ter uma economia de mercado forte é necessária a presença de um Estado forte atuando/regulando o mercado, as atividades econômicas. Para os neodesenvolvimentistas, a redução das desigualdades sociais passa pelo "1. Controle de capital; 2. Expansão do gasto público; 3. Câmbio fixo e redução das taxas de juros e 4. A promoção da equidade social" (CASTELO, 2010, P. 200).

$\mathrm{Na}$ verdade, segundo Castelo (2010), a atuação desse Estado visa, tão somente, fortalecer os interesses dominantes sob a hegemonia burguesa industrial. Assim, o Estado explicita sua verdadeira função na contemporaneidade: atuar em favor do capital/ burguesia rentista. Destacamos também a existência de um equívoco na análise realizada pelos neodesenvolvimentistas, quando afirmam a existência de um embate entre a "burguesia rentista" (setores financistas) e a "burguesia produtiva" (setores industriais), como se houvesse uma separação/uma contradição entre elas. Isso não ocorre, pois, como afirma Castelo (2010: 200), “cada vez mais os grandes oligopólios e monopólios transnacionais produtivos operam segundo a lógica da financeirização."

Desse modo, fica evidente a subordinação do desenvolvimento social ao crescimento econômico e à acumulação do capital com subordinação do Estado ao mercado. $\mathrm{O}$ neodesenvolvimentismo recolocou a política social, desvinculando-a da universalização dos direitos o que contribui para o rearranjo da economia capitalista. O neodesenvolvimentismo acaba sendo uma estratégia ideopolítica, baseada em concepções compatíveis com as políticas de estabilização macroeconômica. Em síntese, torna-se uma falsa alternativa ao neoliberalismo, pois não resolve os problemas estruturais da sociedade capitalista, muito menos atende as condições de trabalho e de reprodução social daqueles que verdadeiramente produzem a riqueza, os trabalhadores.

Em consonância com Fagnani (2011), a política social, a partir de 2003, insere-se numa longa fase de tensões entre paradigmas, presentes desde 1990. O Estado Mínimo, hegemônico na agenda das instituições de fomento internacional, não era compatível com o 
Estado de Bem-Estar da Carta de 1988: seguro social versus seguridade social; focalização versus universalização; assistencialismo versus direitos; privatização versus serviço público; desregulamentação e contratação flexível versus direitos trabalhistas e sindicais.

A partir de 2006, o projeto "social-desenvolvimentista", formulado antes da eleição de 2002, foi parcialmente resgatado e impulsionado pelo comércio internacional favorável. O crescimento teve repercussões positivas sobre o mercado de trabalho, transferências de renda da seguridade social e gasto social. O principal item de ampliação consistiu nas transferências de renda da seguridade social, sobretudo em função da valorização do salário mínimo. Mas, além das transferências monetárias às famílias, os gastos sociais também foram impulsionados na expansão da oferta de serviços sociais.

Todavia, os desdobramentos da crise financeira internacional (entre 2011 e 2014) limitaram o crescimento. Mesmo assim, a economia cresceu e distribuiu renda, fato inédito nos últimos 50 anos. Reconhecer esse fato não implica confirmar a ideia de que teria sido implantado um novo modelo de desenvolvimento. Da mesma forma, um conjunto de problemas crônicos e estruturais não foi enfrentado, em grande medida por causa do modelo de transformação lenta que tem pautado os governos do Partido dos Trabalhadores que procuraram fazer a inclusão social sem rupturas com a ordem econômica e esse modelo explica, de certa forma, o fato de muitos retrocessos nos direitos sociais (Fagnani, 2016).

O rebatimento da contrarreforma do estado é visível na saúde que, mesmo sendo constitucionalmente uma política pública e universal (o SUS representa uma das maiores conquistas da classe trabalhadora no Brasil), tem convivido com ataques por parte do Estado neoliberal contra seu potencial democratizante.

\section{Atuais desafios da política de saúde}

Segundo BRAVO (2009), pode-se caracterizar a Política de Saúde, atualmente, ressaltando as tensões e propostas entre os dois grandes projetos em confronto: o Projeto de Reforma Sanitária construído nos anos 1980 e inscrito na Constituição Brasileira de 1988 e o Projeto de Saúde, articulado ao mercado, ou privatista, hegemônico na segunda metade da década de 1990.

O projeto de Reforma Sanitária tem como eixo o Estado Democrático de Direito, que vê a saúde como direito do cidadão e dever do Estado, visando a universalidade do acesso à 
saúde pautada no atendimento integral e a descentralização do financiamento, colocando o setor privado como complementar, trazendo a hegemonia do poder estatal frente aos atendimentos na área da saúde.

Cabe-se destacar a evidência e persistência de diversos problemas na atual conjuntura que rebatem questões como financiamento, organização, infraestrutura e gestão, clientelismo político, fisiologismo e favoritismo; debilidade da base de sustentação política; falta de compromisso com os serviços públicos e deficiência no suprimento de insumos, como observamos na fala de PAIM (2008).

Segundo Vasconcelos (2013), no capitalismo, a capacidade dos governos nacionais de impor-se é enfraquecida por um Estado cada vez mais regido por interesses corporativos, o que resultou na implementação do SUS, após a Constituição de 1988, sem a superação de duas questões essenciais: a superação do "Modelo Médico Assistencial Privatista", centrado no hospital/médico/doença e a superação da subserviência da área da saúde (dos profissionais médicos e das demais áreas, e esta conjuntura de privatização da saúde se reflete diretamente, inclusive, na gestão em saúde) aos interesses do Complexo Médico Industrial (CMI).

Assim, o processo de implementação dos direitos sociais na Constituição de 1988 e o Sistema Único de Saúde dele decorrente, proposta de fortalecimento de uma formação em saúde que seja pautada nos princípios e diretrizes desse sistema de universalidade, integralidade, interdisciplinaridade, intersetorialidade, dentre outros, é acompanhada por uma realidade de contradições, próprias da sociedade capitalista.

Os serviços de saúde tornam-se cada vez mais espaços de supercapitalização e relevante fonte de maximização do capital, em resposta à crise capitalista dos anos 1970: indústria de medicamentos e equipamentos médico-hospitalares, sistema público de saúde, redes de hospitais, clínicas, farmácias, planos privados de saúde, seguros saúde, bolsa de valores, linhas de crédito e financiamento bancários, entre outros. O Estado brasileiro, é pressionado pelos interesses do grande capital internacional e nacional, mediados pelas agências multilaterais, dentre essas agências, o Banco Mundial ganha destaque como importante formulador e divulgador da racionalidade da contrarreforma.

Desde a criação do Sistema Único de Saúde (SUS), em 1988, o Banco Mundial tem demonstrado interesse no setor de saúde brasileiro, especialmente no que se refere às responsabilidades do Estado e à gestão pública. Três aspectos merecem ser considerados nas análises da relação do Banco com o campo da saúde brasileira: a garantia do direito universal à saúde, a forma de gerir essa política pública e o potencial que esse setor apresenta para a 
acumulação do capital. São aspectos que se encontram intrinsicamente relacionados, evidenciando a dinâmica de intervenção do Banco, bem como sua intencionalidade (Rizzoto, 2016).

As orientações do Banco Mundial para a política de saúde fundamentalmente giram em torno da racionalização dos gastos públicos, da focalização dos serviços prestados e da parceria público-privado, via convênios e contratos de gestão, colocando em questão o direito público, gratuito e universal à saúde. A justificativa de tais medidas, de acordo com o Banco, encontra-se na necessidade de priorizar o atendimento à população mais pobre e vulnerabilizada, ressignificando o princípio da equidade, sob um enfoque distinto do marco legal original do SUS, retirando dele as mediações como a universalidade e a igualdade de acesso.

O processo de ajuste do Estado brasileiro inicia-se no governo Collor de Melo, mas é durante a gestão de oito anos do governo Fernando Henrique Cardoso que a contrarreforma torna-se central, configurando, inclusive, um projeto de "Reforma Administrativa do Estado". Foi nesse projeto que Bresser Pereira inseriu a denominada reforma gerencial na saúde, consubstanciada na Norma Operacional Básica de 1996 (NOB 96), que pode ser considerado o marco inicial da contrarreforma na saúde e que, no entanto, foi apresentada somente como avanço da reforma sanitária e não como um amplo processo de contrarreforma.

Segundo Rizzotto (2000), de fato, a NOB de 1996 corresponde, em parte, a algumas diretrizes desse projeto e das orientações do próprio Banco Mundial, seja no que se refere à plena responsabilização dos municípios e à implementação de pacotes básicos de serviços de saúde, seja na organização de um modelo de atenção à saúde em que os municípios superem o papel exclusivo de prestadores de serviços para se tornarem gestores da política de saúde, seja pela estruturação de subsistemas municipais de saúde, correndo-se o risco de fragmentação do sistema, dentre outros.

A ideologia liberal-privatista, defendida por essa instituição, é constitutiva da visão de mundo de parte da sociedade brasileira, de muitos gestores, trabalhadores, analistas e pesquisadores envolvidos com a política de saúde brasileira que nunca apostaram no SUS como um sistema público universal (RIZZOTTO, 2016).

Concordamos com Rizzotto (2000) que a influência do ideário do banco Mundial no SUS não se efetiva somente como uma imposição de fora para dentro, mas por uma confluência de interesses dos governos, de empresários e de pesquisadores desses países que comungavam da mesma perspectiva ideológica. 
Segundo Mendes (2013), os dados de 2013 da Organização Mundial da Saúde sobre financiamento dos sistemas de saúde mostram que, no Brasil, o gasto público como porcentual do gasto total em saúde é de, apenas, $47 \%$, inferior aos $53 \%$ que constituem o porcentual de gastos privados em saúde (via incentivos fiscais. através de desconto no imposto de renda de despesas com saúde e isenção de impostos de serviços classificados como filantrópicos). As evidências internacionais mostram que todos os países que estruturaram sistemas universais de saúde apresentam uma estrutura de financiamento em que os gastos públicos em saúde são, no mínimo, $70 \%$ dos gastos totais.

Ao analisarmos sua história, podemos observar que o SUS vem sofrendo duros golpes desde a sua criação. O SUS foi regulamentado pela lei 8.080/1990 durante o governo de Fernando Collor, porém houve a necessidade de criação, por meio de mobilização popular, da lei 8.142/1990, em razão de o presidente Collor ter vetado os artigos que tratavam das questões cruciais ao sistema, como o financiamento e a participação social em sua gestão. No governo de Fernando Henrique Cardoso, através da lei 9.656/1998, foi legitimado o mercado dos planos de saúde e posteriormente criou-se uma agência para regular e fiscalizar o setor, por meio da lei 9.961/2000. Porém, desde que foi criada, a diretoria do órgão é composta por representantes dos empresários dos planos de saúde, uma vez que a nomeação ocorre por indicação política.

Vale lembrar que, no apagar das luzes, próximo ao recesso de final de ano, em 17 de dezembro de 2014, foi votada no Congresso a permissão de entrada de capital estrangeiro na assistência à saúde (essa medida é considerada, por movimentos ligados à reforma sanitária, como inconstitucional, de acordo com o artigo 199 da Carta Magna) e, ao alterar o artigo 23 da lei orgânica da saúde (8.080/1990), grupos internacionais de investimento já podem adquirir unidades hospitalares no país, e se favorecerem com o desmantelamento orquestrado do sistema público de saúde. Dessa forma, estão apenas seguindo à risca a cartilha criada por entidades que representam o capital internacional, como o Banco Mundial.

Atualmente, o governo Temer lançou como proposta de governo o documento chamado: "Uma ponte para o futuro". Uma das propostas é o fim das vinculações de receitas da saúde e da educação definidas na Constituição, ou seja, eliminar o compromisso do governo com um patamar mínimo de recursos para as duas áreas. E, assim, o governante poderá realizar cortes ou realocar, retirando sua responsabilidade com a aplicação de recursos para os setores. 
Nos últimos meses, temos observado uma total falta de comprometimento com a área da saúde por parte do governo federal, tratando-a como moeda de troca, uma vez que o setor detém a pasta de maior orçamento da esplanada. $\mathrm{O}$ atual ministro de saúde, Ricardo Barros $(\mathrm{PP}-\mathrm{PR})^{2}$, foi um dos mais beneficiados por doações da saúde suplementar na campanha de 2015. Em contrapartida, os planos de saúde cobram suas doações e vão continuar a atacar o SUS por meio dos políticos que representam seus interesses. Qual seria a consequência de tamanhas doações de campanha? Como exemplo disso tivemos a Medida Provisória 627/2013³, Veto à CPI dos Planos de Saúde ${ }^{4}$, e a Emenda Constitucional 95/2016 (que veremos adiante), entre outros.

O atual ministro de saúde aposta nos planos populares, anunciados em julho de 2016, como forma de agradar o empresariado. No contexto de sua proposta, já anunciou que pretende reduzir o controle da Agencia Nacional de Saúde (ANS) sobre a qualidade dos planos de saúde, permitindo a redução das coberturas e a criação de barreiras de acesso. Formas de aliviar a pressão de ações judiciais sobre os planos de saúde para garantia de atendimento também estão em debate. O ministro, em agosto de 2016, criou um grupo de trabalho para elaborar uma proposta concreta, composto por representantes do Ministério da Saúde, da ANS e da Confederação Nacional das Empresas de Seguros Gerais, excluindo toda a sociedade do debate.

Os planos de saúde surgiram no século XIX e precedem a organização dos sistemas de saúde universais. Planos privados são esquemas indenizatórios, contemporâneos a negociações baseadas na retribuição de valores ou prestação de serviços para doenças, para problemas que haviam ocorrido. Esses esquemas mostraram-se inadequados porque deixam descobertos idosos, desempregados, estudantes e voltam-se apenas ao tratamento e não à prevenção. Por isso, foram substituídos por sistemas públicos abrangentes. A Inglaterra, que possui um sistema universal público desde os anos 1940, tem resultados de saúde e financeiros superiores ao de países que mantém um setor privado assistencial forte (BAHIA, 2016).

No Brasil o que se está chamando de "Plano de Saúde Popular" não é novidade na história do SUS. O ataque às diretrizes constitucionais no âmbito da saúde vem sendo reeditado em contextos de crise econômica, em que o capital é financiado pelas finanças públicas ao passo que se diminui alocação de investimentos nas áreas sociais.

Segundo Teodoro (2016), as empresas de saúde vinculam qualidade e eficiência dos serviços prestados à lógica administrativa empresarial. Entretanto, a proposta dos "planos 
populares" ignora que o setor privado de planos de saúde no Brasil só sobrevive porque recebe o repasse sistemático de recursos públicos. Nesse sentido, ao induzir a expansão desse mercado da saúde, amplia-se também a pressão sobre as contas públicas.

Além disso, tal proposta atenta contra o crescente rigor da Agência Nacional de Saúde (ANS) em relação à prestação de serviços precários por parte das operadoras de planos. Como consta no site da Agência, somente em julho desse ano foram suspensas a "comercialização de 35 planos de saúde de 08 operadoras, em função de reclamações relativas à cobertura assistencial, como negativa e demora no atendimento" (site da ANS, 2016). Com a oferta de planos mais precários, a iniciativa do ministro interino fragiliza essa normatização perseguida pela ANS e, ao propiciar a insatisfação com a rede privada, nada indica que haverá qualquer redução da demanda por serviços no Sistema Público.

Cabe lembrar também que a indução à procura de planos precários revela ainda a orientação hospitalocêntrica da medida. A prevenção evita expressivamente a proliferação de doenças graves, contribuindo para conter a elevação dos custos de tratamento complexos nos sistemas. Se realmente houvesse preocupação com qualidade na prestação dos serviços de saúde e com recursos públicos, deveriam aprofundar o modelo preventivista que norteia o SUS (Teodoro, 2016).

Porém, o ápice do tipo de política fiscal protagonizada pelo governo de Michel Temer em relação à austeridade está sendo a defesa de teto para as despesas primárias do governo federal. Como medida de longo prazo, o governo propõe estabelecer um "Novo Regime Fiscal" por meio de uma emenda constitucional ${ }^{6}$ que cria, por 20 anos, um teto para crescimento das despesas públicas vinculado à inflação. Enquanto a população e o PIB crescem, os gastos públicos ficariam congelados.

Segundo artigo publicado pela Fundação Friedrich Ebert Stiftung e a Sociedade Brasileira de Economia Política (2016), a nova regra implicaria reduzir a despesa primária do governo federal em cerca de 20\% do PIB em 2016 para algo próximo de 16\% do PIB até 2026 e de $12 \%$ em 2036. Logo, para que o teto global da despesa seja cumprido - tendo em vista que algumas despesas, como os benefícios previdenciários, tendem crescer acima da inflação - os demais gastos (como Bolsa Família e investimentos em infraestrutura) precisarão encolher de $8 \%$ para $4 \%$ do PIB em 10 anos e para 3\% em 20 anos, o que pode comprometer o funcionamento da máquina pública e o financiamento de atividades estatais básicas.

$\mathrm{Na}$ verdade, o que o novo regime se propõe a fazer é retirar da sociedade e do parlamento a prerrogativa de moldar o tamanho do orçamento público, que passará a ser 
definido por uma variável econômica (a taxa de inflação) e impor uma política permanente de redução relativa do gasto público. Quem perde é a população trabalhadora que é a principal beneficiária dos serviços públicos.

A vinculação de recursos para a saúde foi tema de constante debate nos anos 1990, em virtude das diversas crises financeiras enfrentadas pelo sistema para manutenção dos serviços de saúde (Ministério da Saúde; Organização Pan-Americana da Saúde, 2013).

Em 2000, foi aprovada a Emenda Constitucional 29, consolidando o Sistema Único de Saúde. A EC 29 fixou a vinculação dos recursos orçamentários que seriam destinados à saúde pelas três esferas de governo. Pelo texto aprovado, a EC 29 estipulou norma transitória determinando que a União deveria destinar para a saúde, no ano 2000, 5\% a mais sobre o valor de 1999 e, nos anos seguintes, esse valor seria corrigido pela variação nominal do Produto Interno Bruto (PIB). Com ela, o art. 198 da CF passou a tratar da base de cálculo para a aplicação mínima em ações e serviços públicos de saúde (ASPS), regra que perdurou e foi mantida pela Lei Complementar n 141, de 2012 (Ministério da Saúde; Organização PanAmericana da Saúde, 2013).

Contudo, em 2015, houve mudança do método de cálculo do mínimo com ASPS da União, por meio da EC 86, vinculando-se a aplicação mínima a um percentual da Receita Corrente Líquida (RCL), de forma escalonada, como segue: 13,2\% da RCL em 2016, 13,7\% em 2017, 14,2\% em 2018, 14,7\% em 2019 e 15,0\% em 2020. Essa é a regra de aplicação mínima de recursos em ASPS (SULPINO E BENEVIDES, 2016).

Em 2012, dezenas de organizações da sociedade civil lançaram o Movimento Nacional em Defesa da Saúde Pública, que visava trocar a regra antiga por uma nova, pela qual o SUS passaria a receber $10 \%$ da corrente bruta da União. No segundo semestre de 2013, foi aprovada a "lei do Pré-Sal", na qual uma parte dos recursos seria destinada para financiar despesas com ações e serviços públicos de saúde (ASPS) adicionalmente àquele valor da aplicação mínima. Com a aprovação da EC 86/2015, a partir de 2016, o critério de cálculo para apuração da aplicação mínima correspondeu a um percentual da Receita Corrente Líquida (RCL) do próprio exercício e os recursos do Pré-Sal perderam a condição de financiamento adicional ao da aplicação mínima (FUNCIA, 2015).

Agora, as novas medidas do governo com a EC 95/2015, no que se refere aos pisos definidos na CF para a saúde e a educação, consistem na alteração dos Atos das Disposições Constitucionais Transitórias (ADCT) para que, a partir de 2018, a aplicação seja calculada pela correção do limite mínimo do ano anterior, reajustado pelo IPCA do exercício anterior. 
Enquanto a regra da EC 29 protegia o orçamento federal do SUS por meio da correção pela variação nominal do PIB, a regra proposta incorpora apenas a correção pela inflação, desconsiderando a incorporação das taxas de crescimento da economia ao gasto com saúde e reduzindo a participação do gasto com saúde no PIB (SULPINO E BENEVIDES, 2016).

Importante destacar recente simulação elaborada por técnicos do Instituto de Pesquisa Econômica Aplicada (Ipea) para o caso da saúde, comparando com o que previa anteriormente a EC29 (executado no ano anterior + variação do PIB), ou a progressividade de percentuais sobre a Receita Corrente Líquida ( RCL), vigente a partir deste ano: a) caso essa proposta houvesse sido aplicada a partir de 2003, até o ano de 2015 teria havido uma perda de $42,1 \%$ dos recursos efetivamente aplicados no período, correspondendo a uma subtração equivalente a 257 bilhões de reais; b) sendo implementada a partir de 2017 e considerando 20 anos à frente, apontam perdas entre 654 bilhões e 1 trilhão de reais, dependendo do comportamento das variáveis PIB e RCL (SULPINO E BENEVIDES, 2016).

A EC 95, portanto, impactará negativamente o financiamento e a garantia do direito à saúde no Brasil. Parte do pressuposto equivocado de que os recursos públicos para a saúde já estão em níveis adequados para a garantia do acesso aos bens e serviços de saúde, e que a melhoria dos serviços se resolveria a partir de ganhos de eficiência na aplicação dos recursos existentes. Ademais, a proposta não garantirá sequer o mesmo grau de acesso e qualidade dos bens e serviços à população brasileira ao longo desse período, uma vez que a população aumentará e envelhecerá de forma acelerada.

\section{Formação em saúde: por que valorizar políticas de formação de profissionais dentro do próprio SUS?}

Em 2011, foi aprovada a Política Nacional de Atenção Básica (PNAB), que estabelece diretrizes e normas para a organização da Atenção Básica para a Estratégia Saúde da Família (ESF). A ESF tem como lógica o rompimento da organização disciplinar tradicional, fragmentada e prioritariamente voltada para a dimensão biológica do processo saúde-doença. E deve dar condições para que a equipe multiprofissional seja capaz de estabelecer conexões entre conhecimentos específicos de cada profissão a fim de propor novas práticas.

Em 2007, o Conselho Nacional dos Secretários de Saúde (CONASS) apontou a falta de profissionais com perfil e capacidade técnica para atuar nas equipes como um dos nós críticos mais citados (BRASIL, 2007). Então, desde 2001 o ensino na área da saúde vem sendo orientado pelas Diretrizes Curriculares Nacionais (DCN) na formação geral e específica 
dos futuros profissionais, que também deve estar em consonância com o SUS (BRASIL, 2002).

A partir dos dados e reflexões do relatório da Conferência Nacional de Recursos Humanos de 1993, assim como no documento Norma Operacional Básica de Recursos Humanos para o Sistema Único de Saúde (NOB/RH/SUS), a política de formação de recursos Humanos para o SUS, no Brasil, constatou que o perfil dos profissionais formados não é adequado o suficiente para prepará-los para uma atuação na perspectiva da atenção integral à saúde e de práticas que contemplem ações de promoção, proteção, prevenção, atenção precoce, cura e reabilitação.

Uma das estratégias para se enfrentar tal constatação foi a implantação de cursos de especialização na área de saúde para fortalecimento de políticas públicas e tem sido uma prática habitualmente utilizada pelo Ministério da Saúde. Nessa mesma linha, os cursos de Especialização e Residência Multiprofissional em saúde foram concebidos para dar suporte teórico-prático aos profissionais já inseridos nas equipes e oferecer, em especial, aos recémegressos, uma formação mais voltada às necessidades do SUS.

O processo de aprendizado na Residência Multiprofissional, caracterizado pela formação por meio do trabalho nos serviços, ocorre dentro de um contexto complexo de interações e relações entre preceptores ${ }^{7}$, residentes, coordenadores, tutores e demais profissionais de diferentes áreas do conhecimento, usuários dos serviços e instituições.

A Reforma Sanitária Brasileira influenciou a $8^{\circ}$ Conferência Nacional de Saúde (1986), a Assembléia Nacional Constituinte (1988), as Leis Orgânicas da Saúde (Lei Federal no 8.080/90e 8.142/90) e a Norma Operacional Básica de Recursos Humanos para o Sistema Único de Saúde - NOB/RH-SUS (BRASIL, 2005), instituíram a necessidade de mudanças nos modelos de atenção a saúde e a transformação nos processos formativos de profissionais desta área (BRASIL, 2006). Para tanto, a proposta da Residência Multiprofissional em Saúde (RMS) tem tido ênfase e expansão por propor sinalizar como basilar a educação no mundo do trabalho e para o trabalho.

Os resultados da pesquisa de VASCONCELOS $(2010)^{8}$ revelaram tanto o desconhecimento do Sistema Único de Saúde pelos profissionais de saúde, quanto o reforço por estes do modelo privatizante na saúde e afastamento dos espaços de controle social. Tendo em vista que estes profissionais além de atuarem no sistema também estão formando outros profissionais, a tendência é que está sendo reproduzido um perfil profissional que desconhece a relevância do SUS e seus espaços políticos. 
Dessa forma, esses profissionais podem não se mostrar engajados na defesa da universalidade e da integralidade em saúde e não serem capazes de democratizar com os usuários informações para além dos aspectos clínicos e biomédicos no que se refere à saúde.

Os dados mostram que a concepção de saúde abstrata da OMS continua orientando a prática destes profissionais em detrimento da discussão dos determinantes sociais e econômicos da saúde. Seguindo a mesma perspectiva, nesta pesquisa se constatou que, sobre a contribuição do Movimento de Reforma Sanitária, 45\% dos demais profissionais afirmam desconhecer esta contribuição, isto significa que quase metade do total entrevistado não reconhece a importância deste movimento para a saúde brasileira.

Em um estudo, Aguiar et al (2008) evidenciou que a fratura que ocorre entre o exercício profissional e as possibilidades de prática crítica existente na realidade, relaciona-se anteriormente com o ensino das profissões de saúde, já que em suas diretrizes curriculares, há um esvaziamento de conteúdos essenciais para um projeto de profissão quanto à discussão sobre políticas públicas de saúde.

Observou-se que há um discurso de louvação do SUS, mas a despeito disto, a lógica do ensino e as diretrizes curriculares das profissões de saúde não tendem a fortalecer esse projeto, ao passo que se resumem a apontar conteúdos genéricos, focalizadores, gerando uma fragmentação do ensino, que deixa de garantir conteúdos mínimos referentes a políticas sociais públicas de saúde, garantidores da formação de um perfil profissional crítico formando intelectuais, e não apenas técnicos.

Dessa forma, a diversidade da formação em saúde pode demonstrar as possibilidades e os limites dos profissionais para a realização de ações, que levem em conta, antes de tudo, os princípios socializantes do SUS e as reais necessidades sociais de saúde da população.

A Educação Permanente em Saúde (EPS), enquanto política, se propõe a colocar o SUS como interlocutor na formulação dos projetos político pedagógicos de formação dos trabalhadores, com a finalidade de proporcionar práticas condizentes com os princípios do SUS e que este não seja apenas considerado como um campo de práticas (BRASIL, 2004). Também, que os projetos das instituições formadoras considerem as diretrizes que orientam a criação do sistema: descentralização, universalidade, integralidade e participação social (BRASIL, 2005).

CECCIM e FEUERWERKER, em 2004, já levantavam o problema de que a formação dos profissionais de saúde permanecia alheia ao debate crítico sobre os sistemas de organização do cuidado, defendendo que as instâncias do SUS deveriam cumprir papel 
indutor da mudança tanto do trabalho quanto da formação profissional. Os autores propunham o trabalho articulado entre o sistema de saúde e as instituições formadoras que não podem existir sem a regulação pública e da direção política do SUS. Propondo, dessa forma, a educação em serviço.

Nesse cenário, portanto, uma das políticas desenvolvidas pela Secretaria de Gestão do Trabalho e da Educação da Saúde (SGTES/MS) é a de fomento das Residências Multiprofissionais em Saúde com o objetivo de ser uma pós-graduação para formar em campos de atuação estratégicos para SUS e em regiões prioritárias do país.

\section{Residência em saúde como campos de disputas: projeto sanitário e o projeto privatista}

O Ministério da Saúde (MS) vem apoiando Residências Multiprofissionais em Saúde (RMS) desde 2002 e o estabelecimento de financiamento regular para os Programas de RMS no Brasil. Segundo o Ministério da Saúde, o investimento tem por objetivo, na sua potencialidade pedagógica e política, possibilitar tanto a formação de profissionais quanto contribuir com a mudança do desenho técnico-assistencial do SUS, demonstrando, dessa forma, a centralidade da formação para o trabalho em saúde que, no caso das residências, se torna um espaço privilegiado por se tratar de uma formação no e pelo trabalho.

Na perspectiva de criar uma política de valorização do trabalhador do SUS e de cumprir o Art. 200 da Constituição Federal, foi criada a Secretaria de Gestão do Trabalho e da Educação na Saúde (SGTES) (BRASIL, 2009). Assim, o Departamento de Gestão da Educação, em 2003, começa a desenvolver suas ações pautadas na Política Nacional de Formação e Desenvolvimento para o SUS: Caminhos para a Educação Permanente em Saúde, aprovada pelo CNS, em 2003 (BRASIL, 2009).

Esse contexto possibilita a viabilização da Comissão de Residências em Saúde, a qual propiciou a criação da Comissão Nacional de Residência Multiprofissional (CNRM). Diante disso, é instituída a Lei $\mathrm{n}^{\circ} 11.129$, de 30 de junho de 2005, que estabelece a criação da Residência em Área Profissional da Saúde, excetuada a área médica. Porém, é a Portaria Interministerial MEC/MS no 2.117 que institui a Residência Multiprofissional em Saúde (BRASIL, 2006), estimulando vários grupos a se articularem em diversas regiões do país para construírem novos programas de residência multiprofissional em saúde (BRASIL, 2006).

Em seus princípios norteadores, a RMS aborda a Educação Permanente em Saúde como eixo pedagógico estruturante dos programas e considera este um espaço para o 
desenvolvimento de processo de educação permanente em saúde, dispositivo potencial para promover mudança dos modelos de gestão e atenção do SUS (BRASIL, 2006).

Residência multiprofissional pode ser compreendida como dispositivo de educação permanente, com o objetivo de transformação das práticas profissionais em saúde, com a articulação cotidiana entre ensino e serviço, com base nos princípios da integralidade do cuidado, conduzido por ações interdisciplinares. Consiste em um curso de pós-graduação lato sensu, que se materializa por meio do exercício profissional supervisionado. Entende-se que o programa de Residência Multiprofissional deve oferecer aos profissionais em formação a oportunidade de desenvolver seus saberes de núcleo e campo. O núcleo se refere ao conhecimento específico da categoria profissional e o campo trata dos saberes comuns a serem construídos e compartilhados.

As possibilidades de materialização de uma formação multiprofissional devem ser expressas pelos Projetos político-pedagógicos dos programas, com o objetivo de formar sujeitos capazes de compreender os desafios colocados pelo SUS e intervir diante dessas questões com autonomia.

Ceccim (2009) enfatiza que a maneira multiprofissional de se formar especialistas em serviço é uma proposta amplamente defendida no âmbito do SUS, como tentativa de resposta à diretriz nacional de reestruturação das redes de serviços e cuidado sob o prisma da integralidade. Feuerwerker (2009) expõe um questionamento relevante ao tema: qual é a contribuição concreta desta modalidade de formação? Sobre isso, a autora afirma que a importância do trabalho vivo e das tecnologias leves para o trabalho em saúde justificam o interesse por essa modalidade de ensino-aprendizagem.

A especialização pelo trabalho, segundo ela, pode contribuir para a inovação das práticas em saúde e tem como componente essencial o encontro entre as profissões, oportunidade rara nas graduações, habitualmente pensadas por categoria. Prosseguindo seu raciocínio, Feuerwerker (2009) enfatiza a importância de que a Residência multiprofissional esteja legalmente garantida e normatizada, para que a formação não seja, em algum momento, capturada por interesses outros que não os do sistema de saúde.

Hoje, as RMS encontram-se atreladas ao um contexto de grandes disputas, lutas políticas e sociais, exigindo que os sujeitos envolvidos assumam posição de protagonistas deste processo (LOBATO, 2010). Segundo o discurso oficial desta modalidade de ensino pelo trabalho, a RS constitui-se como uma das estratégias potenciais para repensar o processo de formação em saúde (BRASIL, 2006). Sendo assim, busca-se proporcionar uma nova 
perspectiva teórico-pedagógica convergente com os princípios e diretrizes do SUS, promovendo além do contato entre o mundo do trabalho e o mundo da formação, o desenvolvimento de mudanças de modelo tecnoassistencial em vista às necessidades regionais (BRASIL, 2006).

Interessa-nos saber se, no discurso de qualificação do SUS, o incentivo de políticas públicas, com interferência no modelo educacional, vai contribuir para que a formação profissional esteja na perspectiva da educação permanente ou se é mais uma estratégia de estruturar a rede de saúde por meio de um campo de trabalho precarizado para os profissionais de saúde.

Desde o final dos anos 2000, o Ministério da Saúde vem lançando editais objetivando a mudança da formação e do trabalho em saúde com previsão de fornecimento de bolsas para alunos, preceptores e tutores para o desenvolvimento de atividades de ensino, pesquisas e extensão. ${ }^{9}$ Verifica-se que, na implementação desses programas, o discurso oficial é de que se busca a construção de uma nova consciência sanitária, pedagógica e busca da formação com base na interdisciplinaridade.

Em relação às RMS, suas características são: formação em serviço, supervisão direta por profissionais capacitados (preceptoria), supervisão acadêmica (tutoria), regime de dedicação exclusiva, cenários de formação e práticas em serviços da rede de atenção à saúde nos três níveis de complexidade. Nas Residências, as atividades de formação têm por objetivo desenvolver habilidades e competências para profissionais atuarem em determinadas situações locais de saúde.

Porém, a análise dessa proposta de estruturação e mudança do trabalho em saúde, através do investimento nessa modalidade de ensino, não pode se pautar apenas pelo discurso oficial e, nesse sentido, indagamos o porquê que, ao invés do investimento na qualidade dos serviços de saúde - para que assim o perfil de profissional possa se adequar ao processo de trabalho condizente com as propostas do SUS -, a política de formação vem focando na expansão de vagas para especializações através do trabalho com carga horária elevada (exigindo-se dedicação exclusiva) e salário (bolsa) abaixo do piso normal de um profissional de saúde (apesar da bolsa das residências serem maiores que muitos salários pagos a profissionais de saúde, tanto em algumas empresas privadas quanto em muitos concursos públicos, destaca-se que a carga horária do residente são 60 horas semanais).

Dessa forma, apesar dos esforços do movimento sanitário para uma formação em saúde articulada aos princípios do SUS, atual proposta de residência em Saúde, em tempos 
neoliberais, pode fortalecer ainda mais a lógica do mercado nas políticas de saúde. Observamos a influência neoliberal tanto na substituição de profissionais estáveis e vinculados aos serviços por força de trabalho mais barata, temporária e precarizada, quanto na tentativa de "interiorizar" e expandir ações de saúde no país sob a lógica de inserção de residentes em áreas com a atenção mal estruturada sem garantias de articulação de espaços e profissionais formadores para tutoria, supervisão e docência, o que compromete, além da qualidade da expansão desses serviços, a própria formação.

Desse modo, no que se refere às Residências em Saúde, interessa-nos refletir se, na tentativa de efetivação do SUS em tempos de hegemonia neoliberal, a indução de políticas públicas com interferência direta no modelo de ensino/trabalho educacional vai contribuir para fortalecer a formação e trabalho profissional na perspectiva da Reforma Sanitária ou se pode fortalecer a estratégia de estruturar a rede de saúde através da oferta de um campo de trabalho precarizado para os profissionais de saúde.

Tendo em vista que nessa estratégia de formação pelo trabalho o governo estabelece uma forma de contrato aviltante, temporário e precário para os residentes. Exclui do trabalhador o direito a férias e licença remunerada além do $13^{\circ}$ salário, FGTS, adicional de insalubridade e estabilidade. Obriga os bolsistas a pagarem o INSS como contribuinte individual, sem que haja contribuição patronal ao invés de instituir um plano de carreira para os profissionais da saúde, o que consequentemente fortaleceria de fato o SUS.

Soma-se a este fato a precarização dos serviços de saúde em si, submetendo os profissionais, já inseridos no trabalho no SUS, à dinâmica contrária e aos princípios sanitários do sistema de saúde, tendo em vista a fragmentação da seguridade social, a real precarização da implementações dos cursos de residência pelo país e a falta de integralidade dos serviços, o que compromete a realização de um trabalho multiprofissional e intersetorial. Agregado a essas questões, está a crescente privatização dos equipamentos e da gestão do trabalho em saúde.

Santos (2012) defende que, no caso brasileiro, entre as particularidades da "questão social”, está de um lado a superexploração do trabalho, de outro, uma passivização das lutas sociais que historicamente foram mantidas sob controle do Estado e das classes dominantes. Segundo a autora, a "flexibilização/precariedade" do trabalho entre nós não pode ser creditada somente à crise recente do capitalismo, pois essas características fazem parte da nossa característica de exploração do trabalho. 
A manutenção de um fluxo permanente de demissões e contratações, ou seja, de uma política de substituição dos trabalhadores, que, assim, não conseguem, na sua maioria, ultrapassar os anos iniciais da carreira além de reduzidos custos do passivo trabalhista, reduz também os custos de seleção. $\mathrm{O}$ atual quadro das políticas sociais aprofunda a precarização do padrão de proteção social - por meio da centralidade da assistência social focalista - e a "passivização" dos trabalhadores e movimentos sociais. É fato que se aumenta o grau de precarização e flexibilidade do trabalho, aumenta, na mesma proporção, sua exploração. Sabese da funcionalidade que os processos de precarização e contratação possuem como fonte de "barateamento" do valor trabalho e como sua utilização tem sido cada vez mais recorrente em diversos setores do mundo do trabalho, inclusive nos recursos humanos da saúde.

$\mathrm{Na}$ principal produção sobre residência médica no Brasil, Elias (1987) busca compreender qual seria seu aspecto fundamental: o processo educacional ou o processo de trabalho. Segundo o autor, o estudo das concepções básicas em relação à Residência permitiu identificar duas correntes, denominadas de "pedagógica "e "trabalhista" e reconhecia que ambas apresentavam alguns elementos comuns. Apesar de poderem se reconhecer na residência as dimensões educacionais e a de trabalho, ela não se reduz ou esgota em nenhuma delas.

Assim, a verdadeira característica assumida pela residência será dada pela interação dessas duas dimensões em situações institucionais concretas. O ponto de vista de que a residência é concomitantemente processo de ensino e aprendizado e de trabalho é endossada por Lima (2010) que, ao discutir a "Residência Médica sob a óptica do direito do trabalho", afirma que não há uma dicotomia necessária entre estudo e trabalho na residência. "Pode-se, sim, pensar que o residente, mesmo sendo pós-graduando, exerce atividades laborais e, portanto, pode ter garantidos direitos trabalhistas" (p. 191).

Além da precarização da Política de saúde e do trabalho no SUS, observa-se a dificuldade desses profissionais, inseridos como formadores, de apreender a perspectiva de saúde crítica da Reforma Sanitária e organizar o serviço no modelo multiprofissional e de participação social como demanda o SUS. Fazendo-nos indagar como seria para estes profissionais já formados e inseridos num modelo fragmentado serem responsáveis por formarem novos profissionais com perfil diferente através da colocação dos discentes nesses serviços, cuja tendência é a crescente fragmentação das atividades e rotatividade de profissionais devido à privatização e flexibilização das relações de trabalho. 
Realizamos uma pesquisa ${ }^{10}$ no Instituto de atenção à Saúde, pertencente à Universidade Federal do Rio de Janeiro (HESFA/UFRJ) ${ }^{11}$ que possui programa de Residência Multiprofissional em Saúde, na qual constatamos que há ainda frágil apreensão da determinação social do processo saúde-doença e falta de participação dos preceptores nos espaços coletivos e políticos do SUS. Essa falta de participação pode ser parte e expressão da não apreensão do significado da concepção ampliada e política de saúde do Movimento de Reforma Sanitária, apesar da alta qualificação dos preceptores (especialistas, sendo alguns já mestres) e trabalhando em serviços de referência, a maioria em uma Universidade Federal e estando a mais de três anos envolvido na formação de um curso de residência multiprofissional. A pesquisa sugere também a falta de participação mais efetiva dos preceptores na construção e discussão do projeto Político Pedagógico do curso, a organização do trabalho desenvolvida distanciada do molde multiprofissional e, ainda, a inexistência e fragmentação do planejamento multiprofissional das atividades de ensino (SILVA, 2015).

\section{Considerações finais}

Diante do enfrentamento de uma política de contrarreformas, a afirmação de um projeto profissional e projeto político-pedagógico voltado para uma formação crítica, reflexiva, teórico-metodológica, técnico-operativa e ético-política, é de extrema importância para a formação dos profissionais para o fortalecimento do SUS. Consideramos que no contexto avesso ao SUS universal e de qualidade, uma das alternativas para resistir aos ditames do capital é formar profissionais/intelectuais críticos e consonantes com os princípios e diretrizes do SUS para que a relativa autonomia reservada aos profissionais de nível superior possa ser aproveitada a favor da luta pela saúde coletiva.

É preciso destacar que enquanto a lógica mercantil - nesses moldes atuais de parasita do SUS - não for enfrentada de forma estrutural, seja com o fim do subfinanciamento do nosso sistema de saúde público, seja na disputa do perfil de formação dos trabalhadores da saúde, seja na regulação das especialidades e residências de acordo com as necessidades de saúde da população e não do mercado, seja na criação de estratégias de absorção desses profissionais pelo SUS público e não pela rede privada ou pública terceirizada, o caminho de fortalecimento do SUS será mais dificultoso.

Cabe lembrar que o movimento sanitário entendia que o modelo de assistência à saúde implementado no Brasil durante a ditadura militar - curativo, individual, assistencialista, 
médico-centrado, hospitalocêntrico, superespecializado, orientado para o lucro e favorecimento do complexo médico industrial - era altamente excludente, insustentável financeiramente e incapaz de dar resposta às necessidades de saúde da população. Como alternativa, se propunha a reorientação desse modelo assistencial através da criação de um Sistema Único de Saúde estatal orientado pela atenção básica e guiado por princípios como a universalidade, integralidade e equidade.

Esses dois processos - modelo de atenção e formação em saúde - são quase impossíveis de discutir separadamente e, ainda que se avalie como de imprescindível importância a discussão em torno da formação de profissionais para o SUS, consideramos essencial buscar meios de garantir que o modelo de atenção e do trabalho no SUS atenda aos desafios que estão sendo colocados para a implementação do sistema.

\section{Referências bibliográficas}

AGUIAR, A. M. T; BALTAR, J.F; COELHO, V. H. S; LIMA, R. C. M; MIRANDA, M. C; SILVA, C. S; SILVA, J. F; SOUZA, M. S; VASCONCELOS, A. M. Profissões de saúde, diretrizes curriculares e Sistema Único de Saúde brasileiro (SUS). In: XI Encontro Nacional de Pesquisadores em Serviço Social, ABEPSS, 2008, São Luiz/MA.

AGÊNCIA NACIONAL DE SAÚDE. ANS suspende comercialização de 35 planos de saúde. Disponível em: http://www.ans.gov.br/aans/noticias-ans/consumidor. Acesso em: 10/10/16 às $10 \mathrm{~h}$.

BAHIA, L. Integrante da Comissão de Política da Associação pontua a imprensa nacional e estrangeira sobre o 'tamanho' do SUS. https://www.abrasco.org.br/site/2016/05/repercussoesdas-declaracoes-do-novo-ministro-da-saude-ricardo-barros/. Acesso em 12/10/2016 às 10h.

BRASIL. Resolução 287 de 08 de outubro de 1998. Ministério da Saúde. Brasília. 1998.

BRASIL.Política de educação e desenvolvimento para o SUS: caminhos para a educação permanente e pólos de educação permanente em saúde. Ministério da Saúde. Brasília, 2004.

BRASIL. Conselho Nacional de Secretários de Saúde. Atenção Primária e Promoção da Saúde / Conselho Nacional de Secretários de Saúde. - Brasília: CONASS, 2007.

. A educação permanente entra na roda: educação permanente em saúde: conceitos e caminhos a percorrer. Ministério da saúde. Brasília, 2005

Princípios e Diretrizes para a Gestão do Trabalho no SUS. Norma operacional básica de Recursos Humanos do SUS (NOB/RH-SUS). Ministério da Saúde. Brasília. 2005.

. Residência multiprofissional em saúde: experiências, avanços e desafios / Ministério da Saúde, Secretaria de Gestão do Trabalho e da Educação na Saúde, Departamento de Gestão da Educação em Saúde. - Brasília: Ministério da Saúde, 2006.

Relatório de Atividades da Comissão Nacional de Residência Multiprofissional em Saúde- CNRMS - Exercício 2007/2009. Ministério da Educação, Ministério da Saúde. Brasília, 2009. 
Diretrizes Gerais para os Programas de Residência Multiprofissional e em Profissional de Saúde. Ministério da Educação. Brasília. RESOLUÇÃO No 2, DE 13 DE ABRIL DE 2012.

BRAVO, M.I.S. Política de Saúde no Brasil. In: Serviço Social e Saúde, Formação e Trabalho Profissional. São Paulo: Editora Cortez, 2009.

BEHRING, E R.; BOSCHETTI, I. Política Social: Fundamentos e História. São Paulo. Ed Cortez. 2006.

CASTELO, R. (Org.). Encruzilhadas da América Latina no século XXI. Rio de Janeiro: Pão e Rosas, 2010.

CECCIM R. B. "Ligar gente, lançar sentido: onda branda da guerra" a propósito da invenção da Residência multiprofissional em saúde. Interface (Botucatu), 2009.

CECCIM, R. B.; FEUERWERKER, L. C. M. O Quadrilátero da Formação para a Área da Saúde: Ensino, Gestão, Atenção e Controle Social. In: PHYSIS: Rev. Saúde Coletiva, Rio de Janeiro, 14(1):41- 65, 2004. 2 Disponível http://www.scielo.br/pdf/physis/v14n1/v14n1a04.pdf, acesso em 15/09/2014 as 9h.

CHESNAIS, François. A mundialização do capital. São Paulo: Xamã. 1996.

DRAIBE, S.M. As políticas sociais e o neoliberalismo - Reflexões suscitadas pelas experiências latino-americanas. R e v i s t a U S P. n. 17. 1993

FAGNANI, Eduardo. A política social do governo Lula (2003-2010): perspectiva histórica. In SER Social, Brasília, v. 13, n. 28, p. 41-80, jan./jun. 2011.

O mercado contra a cidadania. IN Portal Vermelho, 15 de fevereiro de 2016. Disponível em: http://www.vermelho.org.br/noticia/276284-2. Acesso em 20 de Maio de 2016.

ELIAS, Paulo E. M. Residência médica no Brasil: A institucionalização da ambivalência. São Paulo, 1987. Dissertação (Mestrado) Departamento de Medicina Preventiva, Faculdade de Medicina da Universidade de São Paulo.

FEUERWERKER L. No olho do furacão: contribuição ao debate sobre a Residência multiprofissional em saúde. Interface (Botucatu), 2009.

FUNCIA, F. Implicações da Emenda Constitucional n. 86/2015 para o processo de financiamento do Sistema Único de Saúde. 2015. Disponível em http://www.conass.org.br/consensus/implicacoes-da-emenda-constitucional-n-862015-para-oprocesso-de-financiamento-sistema-unico-de-saude/, acesso em 13/10/2016 às 14h.

LIMA, A.M.C. Residência Médica sob a Óptica do Direito do Trabalho. REVISTA DA ESMESC, v. 17, n. 23, 2010.

LOBATO, C. P. Formação dos trabalhadores de saúde na residência multiprofissional em saúde da família: uma cartografia da dimensão política. 2010. Tese (Doutorado em Saúde Coletiva)-Universidade Estadual de Londrina, Londrina, 2010.

MENDES, E. V. 25 anos do Sistema Único de Saúde: resultados e desafios. Estudos Avançados 27 (78), 2013.

MINISTÉRIO DA SAÚDE, ORGANIZAÇÃO PAN-AMERICANA DA SAÚDE. Financiamento público de saúde. Série Ecos - Economia da Saúde para a Gestão do SUS; Eixo 1, v. 1. Brasília: Ministério da Saúde, 2013. 
MINISTÉRIO DA EDUCAÇÃO. Financiamento das bolsas dos Residentes médicos e em área profissional da saúde (Multiprofissional e uniprofissional). Ofício circular $\mathrm{n}^{\circ}$ 16/2016/CGRS/DDES/SESU/SESU-MEC. 2016.

MOTA, A. (Org). As ideologias da contrarreforma e o serviço social. Recife: Ed. Universitária. UFPE, 2010.

PAIM, J.S. Reforma sanitária brasileira: contribuição para a compreensão e crítica. Salvador: EDUFBA; Rio de Janeiro: Fiocruz, 2008.

RIZZOTTO, Maria Lucia Frizon. O Banco Mundial e as Políticas de saúde no Brasil nos Anos 90: um projeto de desmonte do SUS. Campinas, 2000, 260f. Tese (Doutorado em Saúde Coletiva) - Faculdade de Ciências Médicas da Universidade Federal de Campinas, 2000.

RIZZOTTO, Maria Lucia Frizon / CAMPOS, Gastão Wagner de Sousa. O Banco Mundial e o Sistema Único de Saúde brasileiro no início do século XXI. Saúde Soc. São Paulo, v.25, n.2, p.263-276, 2016.

SANTOS, J. S."questão Social" - Particularidades No Brasil - Biblioteca Básica de Serviço Social - Vol. 6. 2012.

SILVA, L. C. Formação e prática na saúde: o processo ensino-aprendizagem na Residência Multiprofissional em Saúde da Mulher a partir do relato dos preceptores. Trabalho de Conclusão de Curso de Especialização. Residência Multiprofissional em Saúde da Mulher no HESFA/ UFRJ. Rio de Janeiro. 2015, Mimeo.

SOCIEDADE BRASILEIRA DE ECONOMIA POLÍTICA (SEP) E FUNDAÇÃO FRIEDRICH EBERT. Austeridade e Retrocesso: Finanças Públicas e Política Fiscal no Brasil. Disponível em: http://plataformapoliticasocial.com.br/, acesso em 11/10/2016 às 11h. SULPINO, F.V; BENEVIDES, R.P.S. Os impactos do novo regime fiscal para o financiamento do Sistema Único de Saúde e para a efetivação do direito à saúde no brasil. IPEA. Brasília, 2016.

TEODORO, R. Porque rejeitar a proposta de planos de saúde precários, 2016. Disponível em: https://www.brasildefato.com.br/2016/08/22/artigo-porque-rejeitar-a-proposta-de-planosde-saude-precarios/. Acesso em 12/10/2016 às 13h.

VASCOnCElos, A. M. A Prática do Serviço Social: Cotidiano e práticas democráticas. Projeto de Pesquisa/Extensão CNPq/FAPERJ/FSS-UERJ, 2009.

.A Prática dos Profissionais de Saúde no Município do Rio de Janeiro. Hospitais Universitários. Projeto de Pesquisa. FSS/UERJ/FAPERJ/CNPq, 2010.

\section{NOTAS}

\footnotetext{
${ }^{1}$ Segundo a Resolução CNRMS no 02, 13 de abril de 2012, caracteriza-se como Residência Multiprofissional em Saúde o programa que for constituído por, no mínimo, 03 (três) profissões da saúde, exceto médico. A Resolução 287/98 do Conselho Nacional de Saúde lista quatorze profissões consideradas da saúde.

${ }^{2} \mathrm{O}$ volume de recursos doados oficialmente pelas operadoras de planos de saúde durante os processos eleitorais tem aumentado exponencialmente. Nas eleições de 2002, 2006, 2010 e 2014 foram repassados os respectivos valores: R \$ 839 mil, R 7 milhões, $\mathrm{R}$ \$ 11 milhões e R \$ 54 milhões.

${ }^{3}$ Foi sancionada como Lei 12.973/2014, pela presidente Dilma Rousseff, criada a partir da MP 627, que teve como relator o, então, deputado Eduardo Cunha, que trata da tributação de empresas no exterior. Porém, Dilma
} 
Rousseff vetou, dentre outros, a anistia de R\$ 2 bilhões às operadoras de planos de saúde que cometerem infrações.

${ }^{4}$ A CPI pretendia investigar aumentos abusivos de mensalidades, perda de direito de usuários, a limitação de procedimentos, a obrigatoriedade para atender mais pacientes por hora, as inúmeras queixas de usuários e profissionais e o fato de alguns dirigentes da ANS terem ligações diretas com planos. Porém, Eduardo Cunha (PMDB-RJ), em março de 2016, vetou a instauração dessa investigação na câmara.

${ }^{5}$ A criação de uma espécie de plano de saúde mais popular, com custos menores, é defendida pelo ministro da Saúde, Ricardo Barros, em uma tentativa de aliviar os gastos do governo com o financiamento do Sistema Único de Saúde (SUS). A proposta de Barros consiste em oferecer planos de saúde com menos serviços do que o que foi definido pela Agência Nacional de Saúde Suplementar (ANS) como cobertura mínima obrigatória.

${ }^{6}$ O plenário da Câmara dos Deputados concluiu em 26 de outubro de 2016 a análise em segundo turno da, então, Proposta de Emenda à Constituição (PEC) 241, o texto seguiu para análise no Senado como proposta de emenda à constituição $n^{\circ} 55$ de 2016. No dia 13 de dezembro de 2016 foi aprovada em sua última votação no Senado. O Congresso Nacional promulgou, então, no dia 15 de dezembro de 2016 a Emenda Constitucional 95/2016, que limita por 20 anos os gastos públicos. Para 2017, a saúde terá $15 \%$ da Receita Corrente Líquida, que é o somatório arrecadado pelo governo, deduzido das transferências obrigatórias previstas na Constituição. A educação, por sua vez, ficará com $18 \%$ da arrecadação de impostos. A partir de 2018, as duas áreas passarão a seguir o critério da inflação (Agência Senado, 2016).

${ }^{7}$ De acordo com a Resolução CNRMS no 2, de 13 de abril de 2012, o tutor é o profissional com formação mínima de mestre e com experiência profissional de, no mínimo, três anos. Sua função caracteriza-se por atividade de orientação acadêmica de preceptores e residentes. Os docentes são profissionais vinculados às instituições formadoras e executoras que participam do desenvolvimento das atividades teóricas e teóricopráticas previstas no Projeto Pedagógico do Curso. Preceptor é o profissional vinculado à instituição formadora ou executora, com formação mínima de especialista. Sua função caracteriza-se por supervisão direta das atividades práticas realizadas pelos residentes. Nos documentos oficiais não há definição de quem é o residente multiprofissional em saúde. Portanto, explicitamos que estes são profissionais formados em áreas de saúde não médicas que são inseridos nos programas de residência como discentes do curso.

${ }^{8}$ A pesquisa se chama: “A Prática dos Profissionais de Saúde no Município do Rio de Janeiro: HU's”, realizada com 349 profissionais de saúde de nível superior, do complexo de saúde universitária da Universidade Federal do Rio de Janeiro (UFRJ) e da Universidade do Estado do Rio de Janeiro (UERJ).

${ }^{9}$ Seguindo a tendência de medidas de cortes do atual governo Temer, o Ministério da Educação (MEC) dirigiu o ofício em setembro de 2016 aos conselhos de residência informando que não ampliará o programa de bolsas para residência (residência médica e em área profissional da saúde - uniprofissional e multiprofissional) para 2017 , em decorrência do corte orçamentário. No texto, diz que as bolsas existentes estão garantidas e que a progressão das bolsas de R1(residentes que estão no primeiro ano do curso) e para R2 (residentes do segundo ano) também não sofrerá alteração. (Ministério da Educação, 2016).

${ }^{10}$ Estudo realizado para o Trabalho de Conclusão da Residência, no qual analisamos o perfil das concepções, teóricas e ético-políticas dos preceptores inseridos na Residência Multiprofissional em Saúde da Mulher do Instituto São Francisco de Assis (HESFA)/Universidade Federal do Rio de Janeiro (UFRJ). A metodologia do estudo foi a pesquisa qualitativa e realizou-se a partir dos relatos dos preceptores que pertencem às seguintes áreas de conhecimento: Serviço Social, Psicologia e Enfermagem. Do total de 41 preceptores, 12 foram entrevistados, dos quais: 4 assistentes sociais, 4 enfermeiros e 4 psicólogos. O estudo está de acordo com a Resolução no 466/2012 do Conselho Nacional de Saúde (CNS) sendo aprovada em 02/10/2016 no Comitê de Ética da Escola de Enfermagem Anna Nery da UFRJ , com numeração 069850/2014.

${ }^{11} \mathrm{O}$ instituto é campus de referência no âmbito da formação e da atenção à baixa e médica complexidade em Saúde e tem como principais diretrizes, no nível docente-assistencial, servir de campo de práticas para alunos de graduação e de pós-graduação da área da saúde, envolvidas com o ensino, a pesquisa, a extensão e a capacitação profissional multidisciplinar. 